\title{
Perception of Economic and Environmental Impact of Christmas Festival/Calabar Carnival in Calabar Metropolis of Cross River State, Nigeria
}

\author{
${ }^{1}$ Edim, M. E. And ${ }^{2}$ Osaji, N. N., \\ ${ }^{1,2}$ Department Of Human Kinetics And Health Education, Faculty Of Education, University Of Calabar, \\ Calabar-Nigeria
}

\begin{abstract}
This study investigates residents' perception of economic and environmental impact of Christmas Festival/Calabar Carnival in Calabar Metropolis of Cross River State, Nigeria. To achieve the objectives of this study, two hypotheses were formulated to guide the study. Literature was reviewed according to the hypotheses directing the study. The survey research design was adopted for the study. A total of two hundred (200) respondents were randomly selected for the study. The selection was done through simple random sampling technique. A questionnaire was designed by the researchers with the help of some measurement experts that gave its face and content validity. To test this hypotheses and to ascertain whether to accept or reject them, Pearson Product Moment Correlation Analysis was considered appropriate because of the nature of variables involved. The 0.05 level of significance was used for the statistical testing of each hypothesis, with critical value and degree of freedom. The results show that there is significant effect of economic and environmental impact of the Christmas Festival/Calabar Carnival on the residents of Calabar Metropolis, in Cross River State, Nigeria. Based on the findings of the study, some conclusions and recommendations were made.
\end{abstract}

\section{Introduction}

The Cross River State Christmas Festival/CalabarCarnival was introduced as a product lined for the state tourism initiative in 2005. This was in recognition of tourism as a strategic economic development tool by Governor Donald Duke led administration in the state between 1999-2008.The Festival/CalabarCarnival which lasts for 32 days begin in December $2^{\text {nd }}$ to $1^{\text {st }}$ January and has many products such as city walk, musical festival, traditional masquerades, Calabar carnival, and certain competitions, such cultural parade, children carnival, adults carnival, boat regatta, and carol night.

The event is regarded as the Africa's biggest street party. It is the most prestigious occasion that has evolved into a major international event with great economic, cultural, political and environmental impact, hence placing Cross River State in an international limelight, (Duke 2005). Tourism according to Duke is a panacea for economic growth. It remains a critical option in the drive for wealth creation and an alternative to dependence on fluctuating oil revenue. It is not surprising that government invest considerably on improving the tourism industry and development of infrastructure to enhance the potential for economic profits.Thoughtourism investments are often based on predictions that economic impact will result from the influx of visitors to the host city and the creation of thousands of new jobs, (Ritchie and Smith, 2001).

However, economic growth following tourism events is not guaranteed and there have been issues of the events bringing about economic havoc rather than development to the state. The 32 days festival is expected generally to stimulate economic growth of the state. Conversely, little attention is paid to careful consumption of natural environment in preparation of the ChristmasFestivals/Calabar Carnival.A well-managed environmental and security programme if well designed can reduce the environmental destruction raised from refurbishment of the transport systemand traffic that leads to degradation of the physical and biological environment by causing air, water and soil pollution as well as security issues that is another challenge linked to tourism events and this has gained attention is recent years (Cashman, 2002). The purpose of this paper is to examine residents' perception of socio-economic and environmental effect of Christmas Festival/Calabar Carnival on the people of CalabarMetropolis in Cross River State, Nigeria.

\section{Literature Review}

The economic role of CalabarFestival/Carnival is based on the fact that they act as catalysts for attracting visitors and increasing their average spending and length of stay in the destination.The Festival/Carnival s contributes to the local regeneration and prosperity of the destination. This is because it generates new employment opportunities (Prentice and Anderson 2003,). There is an agreement among experts that festivals bring about the emergence of small and medium sized enterprises in tourism destinations 
(Bachlestiner and Zins, 2009).The benefits of the CalabarFestival/Carnivalinclude provision of community facility, job creation and the promotion of the area for tourism. (Hall, 2004) opined that economic impact of event "is the total amount of additional expenditure generated with a city that can be directly or indirectly attributed to the staying of a major sporting cultural or religious event". According to Lindberg (1996) that the economic impact studies focuses on the changes that take place in sales, income, jobs, or other parameters generated by the event That the aim of every economic impact study is to assess the net effect of staging the event in the area.

The CalabarFestivals/Carnivalshave the potentials to generate substantial revenue for the state.

Government supports and promotes events as part of their strategies for socio-economic development, nation building and cultural tourism, (Onah, 2007). The CalabarFestival/Carnivalevents are seen by many as important tool for attracting visitors and building image within different communities. The economic impact of the event is measured principally from the consumption of tourism products within a geographical area (Duke, 2005).Tourism activities are bound to intervene with nature and produce changes in the environment (Girginous\&Pary, 2005). In some cases, the environmental impact can be positive and negative. Deco and Baloglu (2002) noted that tourism activities can help preserve the physical environment and local heritage which otherwise might not have happened if the mega event was not held. The impact of the CalabarFestival by evaluation has its effect on the physical environment of the city of CalabarMetropolis.Since tourism is a powerful tool in stimulating economic development, it has been widely used by government to diversify a country's economic base, to stimulate a new economic sector or as part of the regeneration of urban and rural areas to underpin poverty, redevelopment and to create new attraction and activities for tourists (Onah, 2004).

Tourism development in many places may lead to deterioration in environmental quality. The growth of tourism has prompted debates about environmental consequences and the desired ability of further development. Matheson and Wall (1992) opined that the attribution of environmental damage to tourism is difficult for a number of reasons. They further said that the main problem is that of disentangling the effects of tourism from the effects of human existence. Edington and Edington (1986) are of the opinion that a proper understanding of biological or more specifically ecological factors can significantly reduce the scale of environmental damage associated with recreational and tourism development.Gossling (2002) observed that tourism contributes to changes in landuse, energy use, extinction of species, geographical spread of diseases and change to the perception of the environment.He further expressed concern that tourism has increased the levels of transport on roads and in the air during the period of CalabarFestival, and is the consequent of wider effect on the environment and human health. Awareness of pollution emanating from various transport modes as well as direct effects on landscape and amenity values have escalated as transport infrastructure is further developed. Transportation is one aspect of tourism which highlights the conflicts between the environment and the industry.On the other hand, traveling is an essential criterion for tourism, hence roads, cars, aircrafts and airports are all needed to permit the easy passage of tourists from home to destination and back again conversely.The negative effects are the pollution of the natural environment and damage to the quality of landscapes (Gossling, 2002).

In the history of tourism, it has been indicated to be a social event. Tourism is a global phenomenon which is essentially taste driven, with communities in and out of fashion and often the topic of social conversation. This is often embodied in the concept of which places are "in vogue and must see destination. Socio-cultural impact relates to changes in societal value systems, individual behavior, social relationship, lifestyles,modes of expression and community structures (Lea, 2008). The focus of socio-cultural impact tends to be the host community. This could be about the effect of the event on the people of the host communities of their direct and indirect association with tourists.

Murphy (2005) opined that tourism as a vehicle for economic modernization and diversification almost invariably leads to changes and developments in the structure of society. These may be positive and negative.In the positive sense, there may be society-wide improvements in income, employment opportunities, education, local infrastructure and services. While the negative side, there may be a threat posed to traditional social values, the creation of factions of society who may take advantage of others and adaptation or weakening of cultural values. According to Coher (2002), the interaction between host and guest could dilute or destroy traditional cultures or create new opportunities for peace and greater understanding. Onah (2007), said that the negative aspect of the CalabarFestival was much more than the positive aspect. He observed that a proper monitoring programme if put in place will overcome the negative impact of tourism such as crime, lack of security, traffic congestion, inadequate light supplies, sanitation condition, and road network. 


\section{Methodology}

The researcher made use of the survey research design for this study which is meant to describe and interpret the effect of CalabarFestival/CalabarCarnival on the residents of CalabarMetropolis.The population of this study consists of residents of CalabarMetropolis. A total of 200 respondents were randomly selected from the population.

The main instrument used for data collection was the questionnaire.Close ended questions were constructed and administered to the respondents to enable them choose the alternatives that best describes their opinions. The questionnaire contained two parts. Part 1 is focused on the demographic data of the respondents while part 2 contained data on residents perception of socio-economic and environmental effect of the Christmas Festival/Calabar carnival on the people of Calabar metropolis. The instrument used for data collection was validated using factor to content validation. Each item in the questionnaire was formulated to relate to the topic under investigation.To determine the reliability of the instrument used for the study, test retest reliability was conducted on a smaller sample size using Pearson Product Moment Correlation Coefficient(r) and the result yielded 0.07 , this shows a high level of reliability.

Two hypotheses were used for this study thus:

\section{Results}

There is no significant effect of ChristmasFestival/CalabarCarnival on the economy of residents in CalabarMetropolis. The result of the analysis is presented in table 1

\section{Pearson product moment correlation analysis of effect of Christmas Festival/CalabarCarnival on the economy of residents in Calabar Metropolis $\mathbf{N}=\mathbf{2 0 0}$}

\begin{tabular}{llllc}
\hline Variables & $\sum \mathbf{x}$ & $\sum_{\mathbf{x}^{2}}$ & $\sum \mathbf{x y}$ & r-val. \\
\hline Effect of Christmas Festival/CalabarCarnival & $3 \mathbf{y}$ & $\mathbf{y}^{2}$ & & \\
& 3328 & 11075584 & \multirow{2}{*}{6514} & 0.64 \\
Economy of Residents Of CalabarMetropolis & 3186 & 10150596 & & \\
\hline
\end{tabular}

Significant at 0.05 level, $d f=198$, critical $r=.138$

The result of the statistical analysis as presented in table one indicates that the calculated $r$-value of 0.64 is greater than the critical r-value of .138 at 0.05 level of significance with 198 degree of freedom. The result is significant and the null hypothesis was rejected. This means that there is a significant effect of Christmas Festival/CalabarCarnival on the economy of residents in CalabarMetropolis. The second hypothesis reads that:

Environmental indices of the Christmas Festivals/CalabarCarnivalhave no significant effect on residents perception in Calabar Metropolis.The result of the analysis is presented in table 2

Pearson product moment correlation analysis of environmental indices of Christmas
Festivals/CalabarCarnivaland residents perception in Calabar Metropolis $(\mathrm{N}=\mathbf{2 0 0})$

\begin{tabular}{lllll}
\hline Variables & $\sum \mathbf{x}$ & $\sum \mathbf{x}^{2}$ & $\sum \mathbf{x y}$ & r-val. \\
& $\sum \mathbf{y}$ & $\sum \mathbf{y}^{2}$ & & \\
\hline $\begin{array}{l}\text { Environmental indices of Christmas Festivals/Calabar } \\
\text { Carnival }\end{array}$ & 3354 & 11249316 & & \\
Perception of residents in CalabarMetropolis & & & 6540 & 0.701 \\
\hline
\end{tabular}

- $\quad$ Significant at 0.05 level, $d f=198$, critical $r=.138$

The result of the statistical analysis as presented in table two indicates that the calculated $r$-value of 0.701 is greater than the critical r-value of .138 at 0.05 level of significance with 198 degree of freedom. The result is significant and the null hypothesis was rejected. This means that there is a significant effect of Christmas Festivals/CalabarCarnivalon the environmental indices and the perception of residents in of CalabarMetropolis.

\section{Discussion Of Findings}

This section deals with the discussion of findings of the hypothesis directing the study. The result of the first hypothesis indicates that there is a significant effect of the economic impact of ChristmasFestivals/CalabarCarnival in the economy of residents of Calabar Metropolis. The findings of this hypothesis is in line with Duke (2005) who said that the economic impact of the activities are measured principally from the consumption of tourism product, within a geographical area. He went further to say that it 
can also be measured by assessing the net effect of staging the event in that area, and will remain a critical option for wealth drive and creation, and alternative to dependence onfluctuatingoil revenue.

Onah (2007) also asserted that the economic impact of ChristmasFestival/CalabarCarnival has been seen to have provided jobs annually not only in Nigeria but to Cross River State through the visitation of tourists. He went on to say that the increased employment opportunities which emanates from the various hotels, eco-tourism resorts comprising of the national parks, game reserve entertainment sector, transportation, providers of allied accommodation, restaurant operators, snacks bar operators, dealers of souvenir, travel agencies and many others. Also, Ogbe (2007) opined that economic benefit of the events may arise from direct taxation mainly on tourists manpower and transport enterprise from the indirect taxation mainly on goods consumed by the host and tourists.

The result of the second hypothesis indicates that environmental indices of Christmas Festivals/CalabarCarnival has a significant effect on residents of Calabar Metropolis. To support the findings of this study, Deco and Balogu (2002) noted that the tourism events can help preserveor destroy physical environment and local heritage. On their evaluation of the Christmasfestival/Calabar Carnival, it has an effect on the physical environment of the city of Calabar and its neigbouring communities.

Page (2007) supported that the pollution emanating from various transport modes as well as direct effects on landscape and amenity values have escalated as transport infrastructure should be properly developed. Onah (2007) also supported that at the host of this events, the security lapses, the traffic congestion and increased crime during these event are part of the negative environmental impact experienced by residents of CalabarMetropolis. He concluded by saying that although the negative environmental impact of Christmasfestival/Calabar Carnivalwas much more than the positive/impacts, but if a proper monitoring programme is put in place, it will overcome the negative impact of these events.

\section{Conclusion And Recommendations}

Based on the findings of this study, the following conclusions were made:

1. That there is significant effect of economic impact of Christmas festival/Carnival on the residents of CalabarMetropolis

2. There is a significant effect of environmental impact of ChristmasFestival/Calabar Carnival on residents of Calabar Metropolis

Based on the following findings and conclusions of this study, these following recommendations are made:

1. The timing in the organization of the Calabar Carnival should be reviewed

2. Specialized training for effective crowd control for security operatives and band marshals should be conducted

3. Alternative routes should be provided to ease the difficulties encountered by Carnival attendance to the place of events.

\section{References}

[1]. Bachestiner D. \&Zins D. (2009). Management: A programmed approach with cases and application (4 $4^{\text {th }}$ ed). New Delhi: Tata McGraw-Hill

[2]. Cashman, A. \& (2002).Booking tourism with telecommunications.Mofinews:Monthly Journal of Ministry of Finance Incorporated,Calabar 2 (4) 23-26

[3]. Coher, R. (2002). Tourism development in Nigeria.Brochure of Nigeria Tourism Development Corporation 1 (1) 1-3

[4]. Deco E. \&Balogu, A. (2002). The need to harness Nigeria publishers.Abuja:Federal Ministry of Tourism and Trade

[5]. Duke, D. (2005) Mofinews:MonthlyJournal of Ministry of Finance Incorporated, Calabar, Nigeria

[6]. Edington W. \&Edington A. (1986) Tourism: A modern synthesis.Colorado: Stephen Publishers

[7]. Girginous, K. \&Pary, (2005). Introduction to economics $\left(2^{\text {nd }}\right.$ ed). Oxford: Blackwell

[8]. Gossling P. (2002). Road map to a sustainable tourism initiative: The Cross River State Tourism Vision and Policy. Mofinews:Journal of Ministry of Finance Incorporated,Calabar 4 (5) 44-46

[9]. Hall,(2004). Tourism management: Towards the new millennium. Oxford: Pergamon.

[10]. Lea, C. (2008). Critical issues in tourism. Oxford:Free Press.

[11]. Lindberg, T. (1996).Residents' attitude toward tourism impacts in Hawaii. Annuals of Tourism Research 14:17-13

[12]. Matheson, A. \& Wall, G. (1982).Tourism economy, physical and social impacts. Harlow: Longman

[13]. Murphy M. (2002).Tourism geographies. London:Routhledge.

[14]. Onah, G. (2007). The way forward.Mofinews 3 (2) 26-27

[15]. Page, W. B. (2007). Tourism best global industry Mofinews:MonthlyJournal of Ministry of Finance Incorporated, Calabar. 4 (2), $52-53$

[16]. Prentice A. \& Anderson, S. (2003).Journal of sports and tourism Vol. 15, 4, pp 337

[17]. Ritchie, J. B and Smiths F. (2001). Consensus policy formation in tourism management 